\title{
Article
}

\section{The Gradient Effect on the Relationship between the Underlying Factor and Land Surface Temperature in Large Urbanized Region}

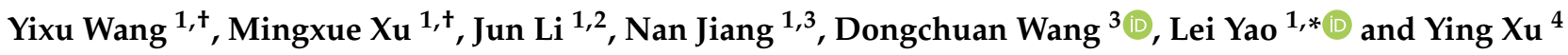 \\ 1 College of Geography and Environment, Shandong Normal University, Jinan 250014, China; \\ wyixu1111@163.com (Y.W.); xumingx1728@163.com (M.X.); 17864193132@163.com (J.L.); \\ 18340085636@163.com (N.J.) \\ 2 School of Geography, Nanjing Normal University, Nanjing 210023, China \\ 3 School of Geology and Geomatics, Tianjin Chengjian University, Tianjin 300384, China; mrwangdc@126.com \\ 4 School of Civil Engineering, Shandong Jiaotong University, Jinan 250023, China; xuy_1986@126.com \\ * Correspondence: alex_yaolei@126.com \\ + These authors contributed equally to this work.
}

Citation: Wang, Y.; Xu, M.; Li, J.; Jiang, N.; Wang, D.; Yao, L.; Xu, Y. The Gradient Effect on the Relationship between the Underlying Factor and Land Surface Temperature in Large Urbanized Region. Land 2021, 10, 20. https://doi.org/10.3390/land10010020

Received: 21 November 2020 Accepted: 25 December 2020 Published: 29 December 2020

Publisher's Note: MDPI stays neutral with regard to jurisdictional clai$\mathrm{ms}$ in published maps and institutional affiliations.

Copyright: () 2020 by the authors. Licensee MDPI, Basel, Switzerland. This article is an open access article distributed under the terms and conditions of the Creative Commons Attribution (CC BY) license (https:// creativecommons.org/licenses/by/ $4.0 /)$.

\begin{abstract}
Although research relating to the urban heat island (UHI) phenomenon has been significantly increasing in recent years, there is still a lack of a continuous and clear recognition of the potential gradient effect on the UHI-landscape relationship within large urbanized regions. In this study, we chose the Beijing-Tianjin-Hebei (BTH) region, which is a large scaled urban agglomeration in China, as the case study area. We examined the causal relationship between the LST variation and underlying surface characteristics using multi-temporal land cover and summer average land surface temperature (LST) data as the analyzed variables. This study then further discussed the modeling performance when quantifying their relationship from a spatial gradient perspective (the grid size ranged from 6 to $24 \mathrm{~km}$ ), by comparing the ordinary least squares (OLS) and geographically weighted regression (GWR) methods. The results indicate that: (1) both the OLS and GWR analysis confirmed that the composition of built-up land contributes as an essential factor that is responsible for the UHI phenomenon in a large urban agglomeration region; (2) for the OLS, the modeled relationship between the LST and its drive factor showed a significant spatial gradient effect, changing with different spatial analysis grids; and, (3) in contrast, using the GWR model revealed a considerably robust and better performance for accommodating the spatial non-stationarity with a lower scale dependence than that of the OLS model. This study highlights the significant spatial heterogeneity that is related to the UHI effect in large-extent urban agglomeration areas, and it suggests that the potential gradient effect and uncertainty induced by different spatial scale and methodology usage should be considered when modeling the UHI effect with urbanization. This would supplement current UHI study and be beneficial for deepening the cognition and enlightenment of landscape planning for UHI regulation.
\end{abstract}

Keywords: urbanization; land surface temperature; built-up land; spatial-statistical modeling; gradient effect; spatial non-stationarity

\section{Introduction}

As one of the most evident features of humans' impact on the Earth's system, the urban heat island (UHI) phenomenon has attracted considerable attention in almost all major cities worldwide [1,2]. It is worth noting that the UHI effect has been exacerbated along with ongoing urban expansion and constant population influx in recent years, presenting substantial adverse threats to both residential and environmental health in and around cities [3-5]. When considering this, scholars across various disciplines have not stopped discussing the topic of UHI, in order to develop deeper understandings on the coupling relationship between $\mathrm{UHI}$ and the urbanization process [6,7]. 
As one of the many factors that influence the urban thermal environment, the landscape features of the underlying surface represent the most commonly used driving factor for examining the quantization relationship with UHI in most of the related studies [8]. This requires the conversion of these environmental factors into quantitative indicators in advance for statistical causal analysis. For UHI, previous studies have tended to use the difference in the surface air temperature (between the urban core and the suburbs) in order to characterize the UHI intensity [9]; with the development of Earth observation technology, the remotely sensed land surface temperature (LST) has been widely used as a more geo-convenient way to record the heterogeneity of the land surface thermal environment $[1,10]$. For investigating the landscape features of the underlying surface, researchers can easily access the detailed land cover and change information for most parts of the Earth's system while using modern remote sensing and geographic information technology. These land surface details can be further quantized into numerical landscape metrics following the landscape ecology theory, and they then fall into two categories, as landscape composition and configuration characteristics [11]. Following this, the spatial and statistical analysis can be employed in order to establish the statistical relationship between these numerical variables, i.e., the dependent (LST or UHI intensity) and independent (landscape indexes) variables.

A previous publication [6] has provided a systematic review of the statistical methodologies that were used in UHI related research, stating that the conventional statistics (e.g., ordinary least squares (OLS)) are the primary ( $>60 \%)$ tools that are employed by researchers in current studies investigating the impacts of underlying factors on UHI variation. However, most of these studies have been conducted within a single city, in order to better serve the planning task of a particular urban region [3,12]. However, multiple cities in economically developed regions gradually tend to exhibit centralization with urbanization, and then form urban agglomeration regions. This regional urbanization process will also have a profound impact on the land surface heat redistribution, so it has attracted the attention of many scholars $[13,14]$. At this point, there is still a lack of research on the broader metropolitan areas of multiple cities. In particular, in these regions, the environmental factors tend to be more complex and heterogeneous over time and space [15]. This presents a challenge to using conventional statistics in large-scale metropolitan areas because of the spatial non-stationarity, which refers to the more spatially varying relationships between the dependent and independent variables [12].

Moreover, UHI and spatial data both have multiscale features, which have been verified to change with different spatial analysis units [16,17]. Generally, the fine-scaled spatial unit can help to better reveal the spatial details of the study area. However, for research areas with various spatial sizes, the scale issue of the spatial analysis unit should be considered based on many external factors, e.g., spatial resolutions of both the land cover and LST data [18], or the modeling efficiency (a large study area with a finer unit means a higher sample size and computational load and vice versa) [17]. For this reason, the use of the spatial analysis unit in previous studies has not presented a unified methodology as a basis, and it has varied with different forms and sizes [19]. This context sensitivity for both $\mathrm{UHI}$ and land surface characteristics may further exacerbate the uncertainty that is posed by spatial-statistical analysis, especially for conventional (global) analysis methods that do not have good spatial suitability.

In general, there is still a lack of a continuous and clear recognition of the change pattern of the UHI-landscape relationship along different spatial gradients in current research. Thus, studying the potential dynamic between the heterogeneous LST and its contributory factors at different spatial scales is essential for providing insights into the dynamic mechanism of UHI [20]. Furthermore, few studies have employed comparative analysis in order to discuss the suitability of different statistical methods in multiscale UHI research [6]. When considering this, we chose a large-scaled urban metropolitan region in China as the case study area, in order to include more spatially complex and heterogeneous LST and land surface underlying characteristics. Subsequently, a comparative analysis that was associated with global- and local-based spatial-statistical models was applied in order 
to evaluate the validity of the results and robustly infer the association of UHI with its driving factors across different sizes of grid units. The results of our study can enhance the understanding of the potential gradient effect on the thermal influence by urbanization.

\section{Methodology}

\subsection{Study Area}

The Beijing-Tianjin-Hebei (BTH) region was selected as the study area, and it is located in the North China plain $\left(36^{\circ} 03^{\prime} \mathrm{N}-42^{\circ} 40^{\prime} \mathrm{N}, 113^{\circ} 27^{\prime} \mathrm{E}-119^{\circ} 50^{\prime}\right)$, covering an area of nearly $2.16 \times 10^{5} \mathrm{~km}^{2}$. This region is dominated by a typical temperate monsoon climate, with an annual mean temperature of $12{ }^{\circ} \mathrm{C}$ and mean precipitation of approximately $500 \mathrm{~mm}$ [21]. Most of the precipitation and hottest temperatures occur in the summer season (June, July, and August), and the winter season is usually cold and dry [14]. The study area includes two municipalities (i.e., Beijing and Tianjin) and 11 prefectural cities (Figure 1). As one of the largest socio-economic urban agglomerations in China, the BTH region has experienced a rapid urbanization process in the past few decades. Until the year of 2015, the population urbanization rate of this region reached $>60 \%$, and 69.7 million people lived in the urban areas $\left(7509.63 \mathrm{~km}^{2}\right)$ [22]. However, dramatic changes of land cover by urbanization have caused serious environmental degradation in this area and they have posed a substantial health threat to the densely populated residents [23].

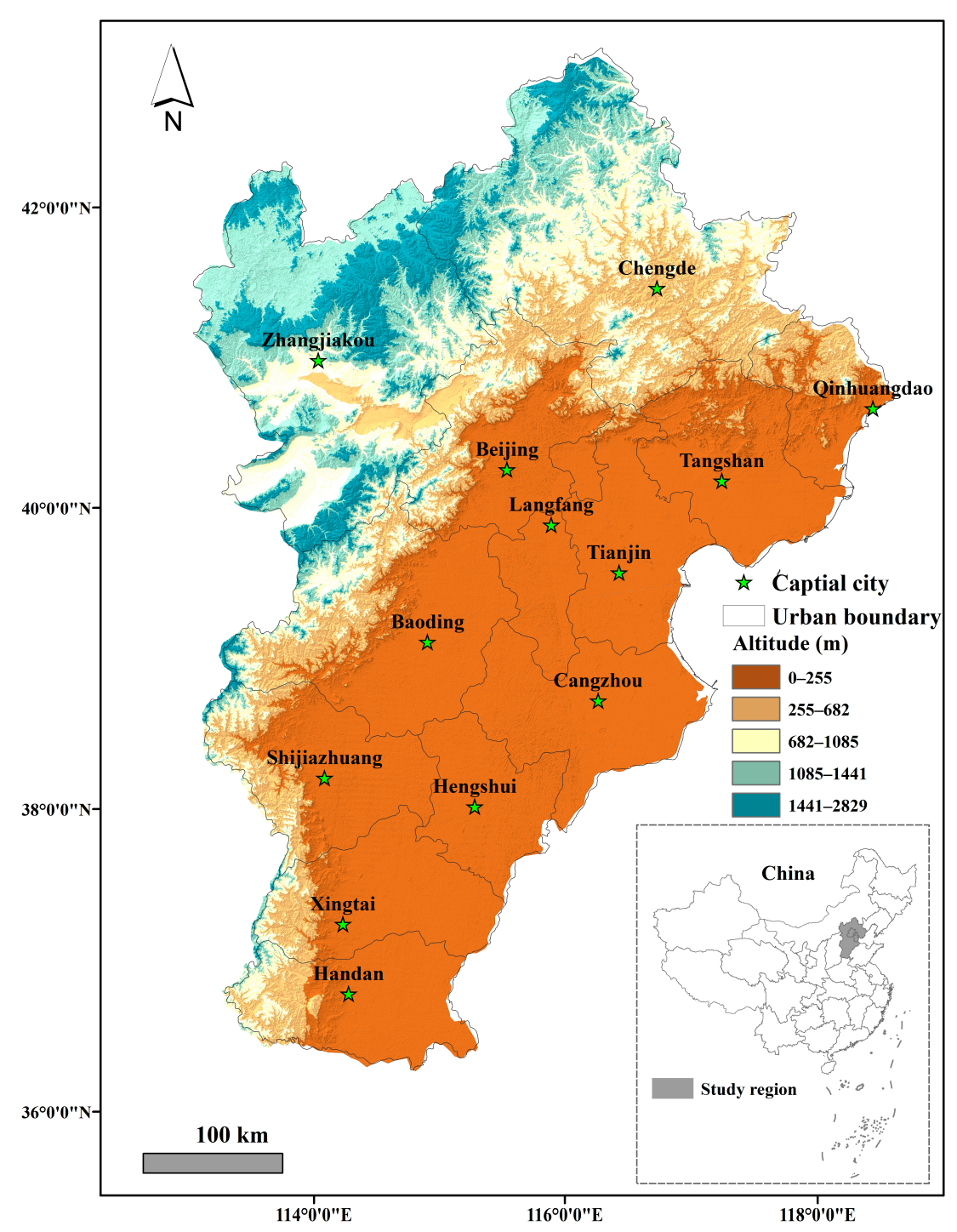

Figure 1. The spatial location of the Beijng-Tianjin-Hebei (BTH) region. 
An increasingly prominent UHI phenomenon is one of these environmental threats, which has been frequently discussed in the BTH region [13,24]. This provided us with the initial impetus to choose this area as an ideal case. Moreover, the BTH region presents additional research advantages for this study. One is that, although the BTH region has experienced significant changes in urban forms, the 13 cities that are within this region are experiencing different levels of urban development [22]. For example, there was a nearly 20-fold GDP gap between the city of Beijing (22,968 RMB) and Hengshui (1220 RMB) in 2015 [21]. Farmland and forest are the dominant land cover types in this region (mainly distributed in the mountainous area), and the urban areas are mainly surrounded by farmland [13]. Various levels of urbanization have formed the underlying landscape with clear spatial heterogeneity at the regional scale, thus providing us with diverse landscape characteristics for discussing our study topic.

\subsection{Land Cover and Land Surface Temperature Data}

There are two types of data source used in this article: land cover and LST data.

The land cover details of the BTH region were identified based on remote sensing technology. The remote sensing images (cloud-free, $<10 \%$ ) were acquired from the Geospatial Data Cloud (http:/ /www.gscloud.cn/), including both Landsat-7 (ETM+, with a spatial resolution of $30 \mathrm{~m}$ ) and -8 (OLI, $30 \mathrm{~m}$ ) data. The acquisition time was during the summer (June to August) in 2000, 2005, 2010, and 2015, respectively. Subsequently, the land cover information was obtained using the backdating interpretation approach (taking the classification result of 2015 as the benchmark reference), for which the detailed procedure can be referred to in $[25,26]$. A total of six types of land cover were eventually divided, as forest, grassland, wetland, farmland, built-up land, and bareland, respectively (Figure 2 and Table 1). The accuracy of all the interpretation results was verified $>95 \%$ [25], in order to fulfill the usage purpose of our study.

The LST data of the BTH region were obtained from the Moderate Resolution Imaging Spectroradiometer (MODIS) daytime datasets. First, the Terra MODIS LST 8-day composite products (observed at 10:30 a.m. local time, with a spatial resolution of $1 \mathrm{~km}$, MOD11A2) that were recorded during the summer season between 2000 and 2015 were downloaded from NASA (http:/ / earthdata.nasa.gov/), and they were retrieved with a generalized split-window algorithm that generally has an absolute bias of $<1 \mathrm{~K}[27,28]$. Second, the LST values $\left({ }^{\circ} \mathrm{C}\right)$ were converted by the surface heat radiation intensity (i.e., the pixel value) of the MOD11A2 datasets by the following conversion formula:

$$
\mathrm{LST}=\mathrm{DN} \times 0.02-273.15,
$$

where $\mathrm{DN}$ is the digital number of MOD11A2 datasets, 0.02 is the radiation scaling ratio (from metadata of the datasets), and 273.15 is the conversion gap between the Kelvin (K) and Celsius temperature $\left({ }^{\circ} \mathrm{C}\right)$. Afterwards, we further composited these LST data (eightday composite) from June to August into single data in order to represent the average LST in the summer seasons of 2000, 2005, 2010, and 2015, respectively (Figure 3). Thus, we adopted these data to conduct the following analysis, by referring to the conclusion of previous studies that the strongest UHI intensity is usually found during the summer season in northern China [29-31].

Table 1. The land cover coverage $\left(\times 10^{3} \mathrm{~km}^{2}\right)$ of the Beijng-Tianjin-Hebei (BTH) region in each period.

\begin{tabular}{ccccccc}
\hline & Forest & Grassland & Wetland & Farmland & Built-Up Land & Bareland \\
\hline 2000 & 70.27 & 18.82 & 6.35 & 101.60 & 17.86 & 0.63 \\
2005 & 71.10 & 19.72 & 6.21 & 98.44 & 19.52 & 0.58 \\
2010 & 71.56 & 19.94 & 6.00 & 95.98 & 21.64 & 0.70 \\
2015 & 70.75 & 19.01 & 5.93 & 93.52 & 25.97 & 0.65 \\
\hline
\end{tabular}


(1)
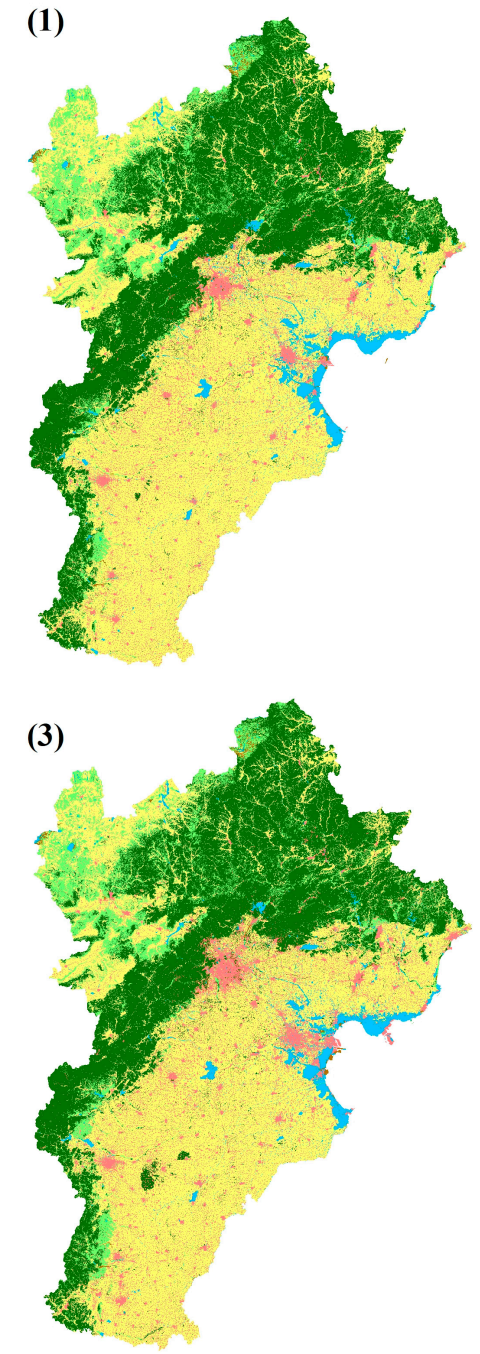

(3)

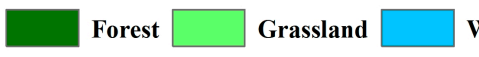

(2)

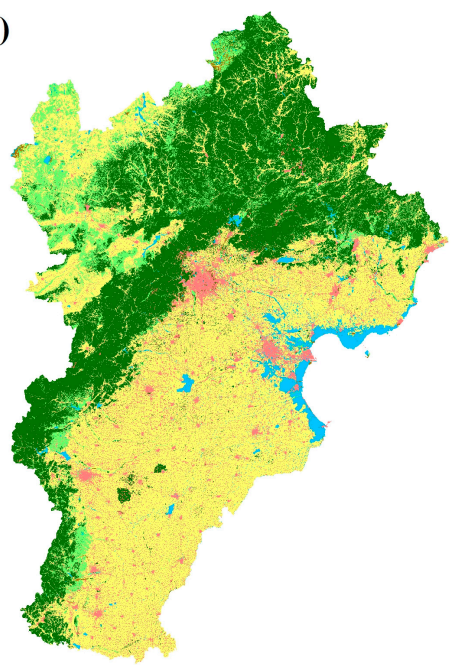

(4)

$\mathrm{N}$

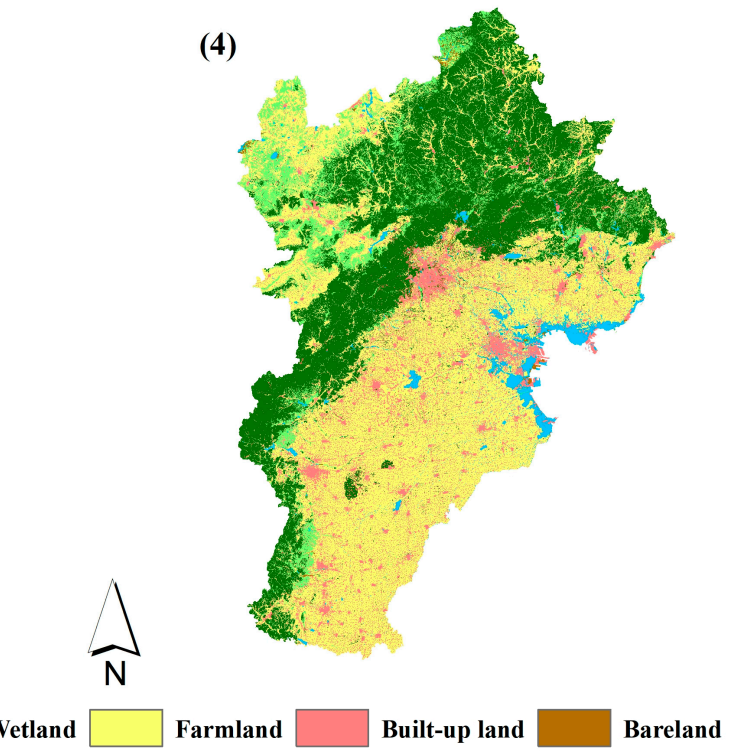

$200 \mathrm{~km}$

Figure 2. The land cover details of the BTH region in (1) 2000, (2) 2005, (3) 2010, and (4) 2015.

\subsection{Grid Analysis Design}

The theory of landscape ecology suggests that multiscale information is required to obtain a better understanding of the relationship between the regional landscape structure and ecological process in the context of spatial heterogeneity [11,32]. This is because both of the elements may have different performances at different spatial and temporal scales, thus leading to complexity in geological/ecological research [33,34]. Therefore, discussing the gradient effect will be beneficial in revealing the potential rules of specific ecological processes.

In research that is related to the urban thermal environment, issues of the gradient/scale effect are often raised, as we summarized in the introduction section. However, the proper analytical unit and its size are still being debated in the literature [35-37]. In this study, we thus applied a multiscale polygon grid-based analysis in order to examine the strength of the relationship between the land cover composition and LST. This approach looks into the statistical relationship between land cover density (LCD) and mean LST, but no proper grid sizes have been suggested by previous studies [38]. Therefore, we simply set up a gradient of different sizes of grid for subsequent comparative analysis, taking 6 , $9,12,15,18,21$, and $24 \mathrm{~km}$ as the analysis scales, respectively. All of the grid sizes were 
designed to be an integer multiple of the pixel size of the thematic data $(1 \mathrm{~km}$ for LST and $30 \mathrm{~m}$ for land cover), in order to ensure that the pixel values of these thematic data within each grid could be effectively summarized.

Subsequently, using spatial overlay analysis, we summarized the two types of thematic information for each grid, i.e., land cover (Figure 2) and LST (Figure 3).
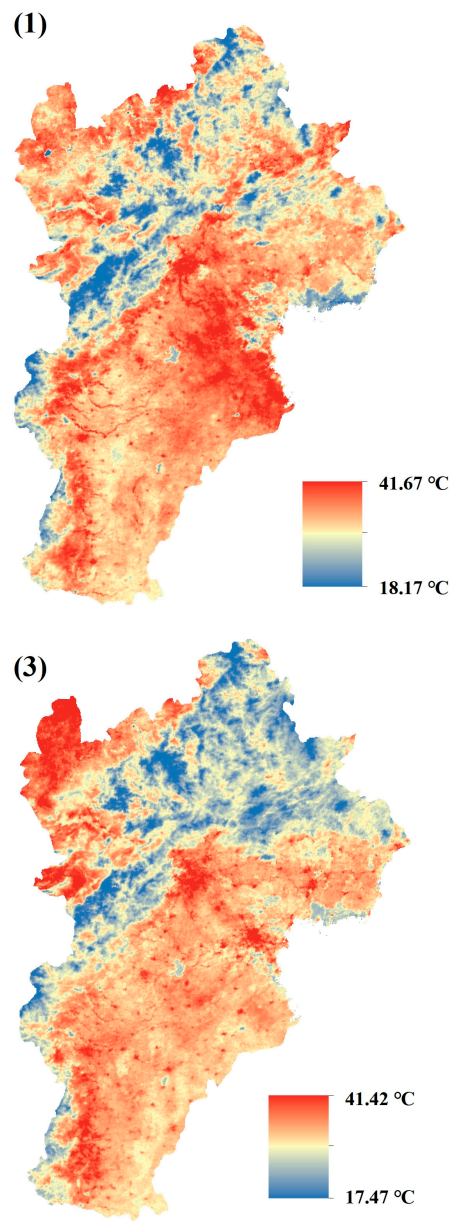

(2)

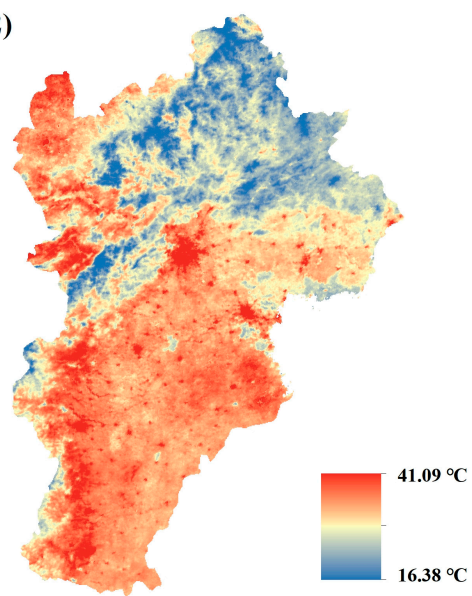

(4)

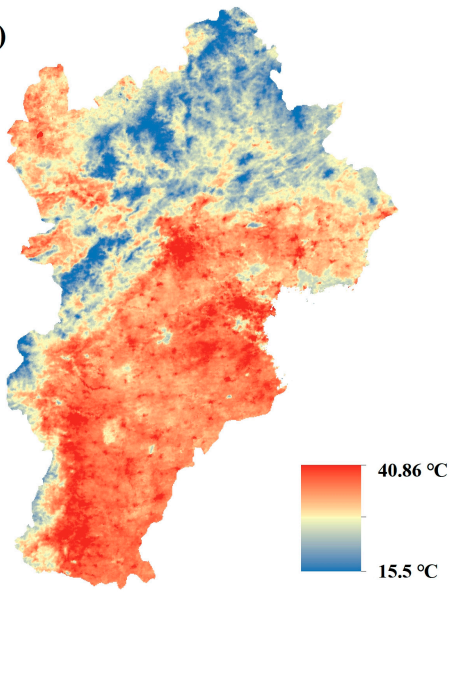

Figure 3. The land surface temperature (LST) for the BTH region in the summer seasons of (1) 2000, (2) 2005, (3) 2010, and (4) 2015.

Specifically, for the land cover data, the density of each type of land cover (\%) was calculated, as follows:

$$
D_{i j}=n_{i j}\left(9 \times 10^{-4}\right) A_{j} \times 100 \%,
$$

where $D$ is the LCD $i=$ [forest, grassland, wetland, farmland, built-up land, and bareland represents the type of land cover, $j=[6,9,12,15,18,21$, and $24 \mathrm{~km}]$ represents the type of grid unit, $n$ is the pixel number for land cover $i, 9 \times 10^{-4}$ is the fixed area for each land cover pixel, and $A_{j}$ is the total area for the $j$ type of grid. For the LST data, the zonal statistics tool in the ArcGIS platform was used to aggregate the mean LST value $\left({ }^{\circ} \mathrm{C}\right)$ for each grid, representing the thermal environment characteristics.

Additionally, all of the (intact) grids were constrained within the study area, in order to obtain complete and correct land cover and LST information. Grids that were located at the edge of the study area were deleted, because of their LCD (the total land cover area $<$ the area of the grid) or LST value (null value). Figure 4 shows a sample graph of the thematic characteristics for different scales of grid. 

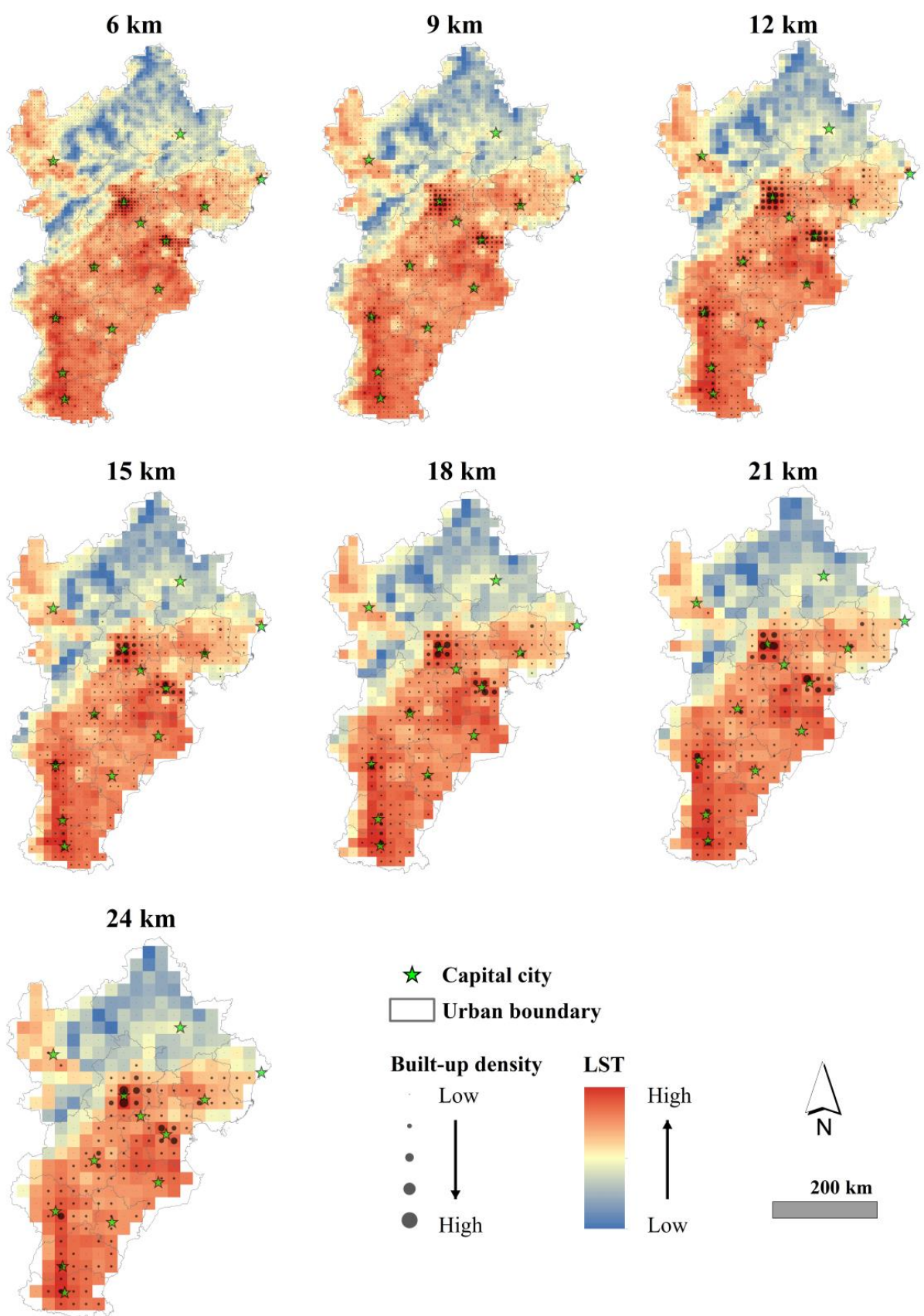

Figure 4. Example of the spatial distribution for summer land surface temperature (LST) and built-up density of the BTH region in 2015.

\subsection{Statistical Analysis}

Previous studies have documented that land use and cover change (LUCC) have been treated as the major driving determinants for the alteration of the surface thermal environment, especially referring to the conversion between natural and artificial construction land $[5,14,39,40]$. In addition, other types of variables, such as landscape pattern characteristics, surface biophysical parameters, socio-economic factors, etc., have also been demonstrated to have significant effects on LST $[36,37,41]$. As stated, the main purpose of this study is to discuss the potential gradient effect in the relationship between the landscape features of the underlying surface and LST in a large region. Under the a priori expectation that LUCC influences LST and, for the sake of simplicity, only LCD was used as the independent variable, while the summer daytime LST was treated as the dependent variable. Both types of variable were processed, as described in Section 2.3 (Figure 4). 
The Spearman correlation matrix was first developed to reveal the bivariate association strength between LST and the density of land cover across the grid sizes and time periods $[19,42]$. This can help to preliminarily determine which type of land cover has the most effective contribution to LST.

Subsequently, based on the results of correlation analysis, we conducted further regression analysis in order to elaborate on the deeper quantitative relationship between the key land cover element and summer daytime LST. The review by [6] concluded that most relevant studies ( $>68 \%$ ) tend to use global-based analysis to quantify the relationship between the spatial variables and UHI variables, of which ordinary least squares (OLS) regression is the dominant method among the reviewed studies. However, when considering the topic of UHI at a regional scale, the UHI effect may show context sensitivity and vary significantly over time and space $[20,43]$. Therefore, it is suggested that the UHI-related phenomenon should be locally modeled for an entire study area. In this study, accordingly, both global-based (OLS) and local-based (geographically weighted regression, GWR) analysis were conducted in order to explore the relationship between LST and the land use density in the BTH region.

OLS regression is a widely used model for quantifying the dependent variable in terms of its relationship with explanatory variable [44,45], with the following equation:

$$
Y=\beta_{0}+\beta X+\varepsilon,
$$

where $Y$ denotes the dependent variable (i.e., the summer LST), $X$ is the explanatory variable (i.e., the built-up density), $\beta$ is the slope coefficient, $\beta_{0}$ is the intercept value, and $\varepsilon$ is a random error term.

The GWR method is one of several spatial regression approaches increasingly used in geography and other disciplines [12,46]. GWR provides a local model for incorporating the spatial characteristics of both dependent and explanatory variables and creating conditions for analyzing the spatial characteristics of the regression relationship, expressed as

$$
Y_{k}=\beta_{0 k}\left(x_{k}, y_{k}\right)+\beta_{k}\left(x_{k}, y_{k}\right) X_{k}+\varepsilon_{k}
$$

where $k$ indicates the $k$ th grid unit, $\left(x_{k}, y_{k}\right)$ represents the spatial coordinates for the grid unit $k$, and the meanings of $Y, X, \beta_{0}, \beta$ and $\varepsilon$ are the same as those of OLS regression. In contrast to the OLS model, the estimation for $Y_{k}$ in the GWR model is mainly determined using limited independent variables $X$ near the location $k$. Each of the independent variables has a specific contribution weight for $Y_{k}$, while that in the OLS model has a weight of unity. A Gaussian distance-decay-based kernel function is commonly used in order to calculate the weight $(W)$ for GWR model while using the following function:

$$
W=\exp \left(-(d / b)^{2}\right)
$$

where $d$ indicates the Euclidean distance between grid unit $k$ and its neighboring grid unit, and $b$ is referred to as the bandwidth parameter. Based on this, the GWR tool will automatically find the optimal distance (for a fixed kernel) by using the Akaike Information Criterion $(A I C c)$-based bandwidth method. More details regarding the two regression methods can be found in [44-46].

Finally, the performances of the OLS and GWR regression models were compared across different grid sizes and time periods. The adjusted coefficient of determination $\left(R^{2}\right)$, the global Moran's I of the standard residuals, and AIC $c$ were used in order to evaluate the performances of the built models with respect to the goodness-of-fit and residual spatial autocorrelation. According to [46], the (adjusted) $R^{2}$ can be interpreted as the proportion of the variance of the dependent variable that is covered by the regression model, which can be used to test the fitness of the regression model (ranging from 0.0 to 1.0, where a larger value indicates a better model fitness). The AIC c can be used to test the model performance and compare the regression models. When considering the complexity of the model, the 
model with a lower $A I C c$ value will better fit the observed data. Comparing the $A I C C$ value of OLS and GWR models is one way to assess their advantages. The $I$ index is used for testing the spatial distribution characteristics of the model standard residuals. If the $I$ index loses its statistical significance $(p>0.05)$, then this indicates that the standard residuals are spatially randomly distributed. These diagnostic factors can also be spatialized (by local Moran's I analysis, etc.) in order to reveal potential findings in depth.

In this study, the statistical analysis of attribute data, e.g., the Spearman correlation analysis, was conducted while using the statistical software of OriginPro. The spatial analysis procedures, such as OLS and GWR regression analysis, were completed using the platform of ArcGIS Desktop [46].

\section{Results}

The Spearman correlation analysis showed that all of the LCDs were significantly related to LST across different grid sizes and periods, except for bareland (in some cases), as shown in Table 2. Among these, the density of built-up land displayed the most significant and positive correlation with the LST variation in all cases, while that of the forest showed the strongest negative correlation. This indicates that the built-up land and forest mainly affected the LST variations in the BTH region. Therefore, we will focus on the performance of this positive driver for the UHI phenomenon in the subsequent analysis, i.e., the built-up land density.

Table 2. The Spearman correlation coefficients for the land cover density and land surface temperature (LST) across different grid sizes and periods (** $p<0.01$ level and ${ }^{*} p<0.05$ level).

\begin{tabular}{|c|c|c|c|c|c|c|c|}
\hline & $6 \mathrm{~km}$ & $9 \mathrm{~km}$ & $12 \mathrm{~km}$ & $15 \mathrm{~km}$ & $18 \mathrm{~km}$ & $21 \mathrm{~km}$ & $24 \mathrm{~km}$ \\
\hline Year & \multicolumn{7}{|c|}{ Forest } \\
\hline 2000 & $-0.50 * *$ & $-0.52 * *$ & $-0.53^{* *}$ & $-0.55^{* *}$ & $-0.58^{* *}$ & $-0.57^{* *}$ & $-0.57 * *$ \\
\hline 2005 & $-0.65^{* *}$ & $-0.66^{* *}$ & $-0.66^{* *}$ & $-0.66^{* *}$ & $-0.68^{* *}$ & $-0.67^{* *}$ & $-0.68^{* *}$ \\
\hline 2010 & $-0.71^{* *}$ & $-0.72 * *$ & $-0.71^{* *}$ & $-0.73^{* *}$ & $-0.74^{* *}$ & $-0.73^{* *}$ & $-0.74^{* *}$ \\
\hline \multirow[t]{2}{*}{2015} & $-0.71^{* *}$ & $-0.72^{* *}$ & $-0.73^{* *}$ & $-0.74^{* *}$ & -0.76 & $-0.76^{* *}$ & $-0.77^{* *}$ \\
\hline & \multicolumn{7}{|c|}{ Grassland } \\
\hline 2000 & $-0.10^{* *}$ & $-0.16^{* *}$ & $-0.19^{* *}$ & $-0.21^{* *}$ & $-0.25^{* *}$ & $-0.28^{* *}$ & $-0.26^{* *}$ \\
\hline 2005 & $-0.16^{* *}$ & $-0.19^{* *}$ & $-0.20^{* *}$ & $-0.20^{* *}$ & $-0.22^{* *}$ & $-0.25^{* *}$ & $-0.22 * *$ \\
\hline 2010 & $-0.06^{* *}$ & $-0.09^{* *}$ & $-0.09^{* *}$ & $-0.10^{* *}$ & $-0.11^{* *}$ & $-0.15^{* *}$ & $-0.13 *$ \\
\hline \multirow[t]{2}{*}{2015} & $-0.34^{* *}$ & $-0.38^{* *}$ & $-0.39 * *$ & $-0.39 * *$ & $-0.40^{* *}$ & $-0.42^{* *}$ & $-0.43^{* *}$ \\
\hline & \multicolumn{7}{|c|}{ Wetland } \\
\hline 2000 & $0.38^{* *}$ & $0.39^{* *}$ & $0.40^{* *}$ & $0.42^{* *}$ & $0.44^{* *}$ & 0.42 ** & $0.37 * *$ \\
\hline 2005 & 0.30 ** & $0.28^{* *}$ & $0.28^{* *}$ & $0.28 * *$ & $0.29^{* *}$ & $0.27^{* *}$ & $0.24^{* *}$ \\
\hline 2010 & $0.33^{* *}$ & $0.33^{* *}$ & $0.33^{* *}$ & $0.35^{* *}$ & $0.35^{* *}$ & $0.33^{* *}$ & $0.30^{* *}$ \\
\hline \multirow[t]{2}{*}{2015} & $0.37^{* *}$ & $0.36^{* *}$ & $0.36^{* *}$ & 0.36 ** & $0.37^{* *}$ & $0.35^{* *}$ & $0.33 * *$ \\
\hline & \multicolumn{7}{|c|}{ Farmland } \\
\hline 2000 & $0.49^{* *}$ & 0.52 ** & $0.53^{* *}$ & $0.55^{* *}$ & $0.58 * *$ & $0.59^{* *}$ & $0.58 * *$ \\
\hline 2005 & $0.56^{* *}$ & 0.58 ** & $0.59^{* *}$ & $0.60^{* *}$ & $0.63^{* *}$ & $0.63^{* *}$ & $0.63^{* *}$ \\
\hline 2010 & 0.56 ** & $0.58 * *$ & $0.59 * *$ & $0.61 * *$ & $0.64^{* *}$ & $0.64^{* *}$ & $0.64 * *$ \\
\hline \multirow[t]{2}{*}{2015} & $0.61^{* *}$ & $0.63^{* *}$ & $0.65^{* *}$ & $0.66^{* *}$ & $0.68^{* *}$ & $0.68^{* *}$ & $0.70 * *$ \\
\hline & \multicolumn{7}{|c|}{ Built-up land } \\
\hline 2000 & $0.54^{* *}$ & $0.56^{* *}$ & $0.58 * *$ & $0.59^{* *}$ & 0.62 ** & 0.62 ** & $0.61^{* *}$ \\
\hline 2005 & $0.65 * *$ & $0.65^{* *}$ & $0.66^{* *}$ & $0.66^{* *}$ & $0.67^{* *}$ & $0.66^{* *}$ & $0.65 * *$ \\
\hline 2010 & $0.68^{* *}$ & $0.70^{* *}$ & $0.70^{* *}$ & $0.70^{* *}$ & $0.72 * *$ & $0.73^{* *}$ & $0.71^{* *}$ \\
\hline \multirow[t]{2}{*}{2015} & 0.79 ** & $0.80^{* *}$ & $0.81^{* *}$ & $0.82^{* *}$ & $0.83^{* *}$ & $0.82^{* *}$ & $0.83^{* *}$ \\
\hline & \multicolumn{7}{|c|}{ Bareland } \\
\hline 2000 & 0.04 ** & $-0.14^{* *}$ & $-0.15^{* *}$ & $-0.14^{* *}$ & $-0.16^{* *}$ & $-0.17^{* *}$ & -0.14 * \\
\hline 2005 & 0 & $-0.21^{* *}$ & $-0.22^{* *}$ & $-0.22^{* *}$ & $-0.22^{* *}$ & $-0.23^{* *}$ & $-0.16^{* *}$ \\
\hline 2010 & $0.03 *$ & $-0.12^{* *}$ & $-0.11^{* *}$ & $-0.08 *$ & -0.08 & -0.08 & -0.02 \\
\hline 2015 & $-0.04 *$ & $-0.23^{* *}$ & $-0.24^{* *}$ & $-0.21^{* *}$ & $-0.21^{* *}$ & $-0.19^{* *}$ & $-0.18^{* *}$ \\
\hline
\end{tabular}

The global regression models estimated statistically significant $(p<0.01)$ relationships for the built-up density and LTS for all cases, as shown in Table 3. Generally, from the year 2000 to 2015, the global $R^{2}$ for these models exhibited an increasing trend. Moreover, 
in each year, the higher $R^{2}$ showed that the OLS models have a better measurement of goodness of fit as the grid scale increases. However, the standard residuals for all of the OLS models displayed significant spatial clustering (i.e., spatial correlation) characteristics $(I, p<0.01)$, which indicated that the OLS model may not be suitable for quantifying the relationship between the built-up density and LTS in a relatively large region.

Table 3. Comparison of ordinary least squares (OLS) regression and geographically weighted regression (GWR) for the built-up density and LST across different grid sizes and periods: Summary of the coefficients and diagnostics. $R^{2}$ is the adjust coefficient of determination, AICc is the corrected Akaike Information Criterion, and I is the global Moran's I of the standard residuals $\left({ }^{* *} p<0.01\right.$ level).

\begin{tabular}{|c|c|c|c|c|c|c|c|c|c|c|c|c|}
\hline & \multicolumn{6}{|c|}{2000} & \multicolumn{6}{|c|}{2005} \\
\hline & \multicolumn{3}{|c|}{ OLS } & \multicolumn{3}{|c|}{ GWR } & \multicolumn{3}{|c|}{ OLS } & \multicolumn{3}{|c|}{ GWR } \\
\hline & $R^{2}$ & $A I C c$ & $I$ & $R^{2}$ & $A I C c$ & $I$ & $R^{2}$ & $A I C c$ & $I$ & $R^{2}$ & $A I C c$ & $I$ \\
\hline $6 \mathrm{~km}$ & 0.17 & 24479.17 & $0.77^{* *}$ & 0.87 & 15270.01 & $0.14^{* *}$ & 0.27 & 24862.14 & $0.86^{* *}$ & 0.94 & 12315.42 & 0.09 ** \\
\hline $9 \mathrm{~km}$ & 0.19 & 10476.87 & $0.76^{* *}$ & 0.88 & 7059.24 & $0.06^{* *}$ & 0.29 & 10733.62 & $0.85^{* *}$ & 0.94 & 6013.16 & 0.02 \\
\hline $12 \mathrm{~km}$ & 0.21 & 5691.60 & $0.73^{* *}$ & 0.82 & 4038.76 & $0.12^{* *}$ & 0.31 & 5872.62 & 0.83 ** & 0.92 & 3462.75 & 0.00 \\
\hline $15 \mathrm{~km}$ & 0.23 & 3533.23 & $0.68^{* *}$ & 0.83 & 2722.49 & 0.01 & 0.31 & 3672.54 & $0.81^{* *}$ & 0.92 & 2234.09 & 0.03 \\
\hline $18 \mathrm{~km}$ & 0.25 & 2356.31 & $0.65^{* *}$ & 0.83 & 1870.14 & -0.01 & 0.33 & 2478.83 & $0.78^{* *}$ & 0.92 & 1500.88 & 0.00 \\
\hline $21 \mathrm{~km}$ & 0.26 & 1685.72 & $0.61^{* *}$ & 0.79 & 1283.56 & 0.04 & 0.34 & 1767.62 & $0.75^{* *}$ & 0.92 & 1113.38 & -0.04 \\
\hline \multirow[t]{4}{*}{$24 \mathrm{~km}$} & 0.28 & 1243.35 & $0.58^{* *}$ & 0.81 & 987.34 & -0.05 & 0.35 & 1323.79 & $0.74^{* *}$ & 0.91 & 836.45 & -0.06 \\
\hline & \multicolumn{6}{|c|}{2010} & \multicolumn{6}{|c|}{2015} \\
\hline & \multicolumn{3}{|c|}{ OLS } & \multicolumn{3}{|c|}{ GWR } & \multicolumn{3}{|c|}{ OLS } & \multicolumn{3}{|c|}{ GWR } \\
\hline & $R^{2}$ & $A I C c$ & $I$ & $R^{2}$ & $A I C c$ & $I$ & $R^{2}$ & $A I C c$ & $I$ & $R^{2}$ & $A I C c$ & $I$ \\
\hline $6 \mathrm{~km}$ & 0.27 & 23948.98 & $0.81^{* *}$ & 0.93 & 12600.87 & $0.09^{* *}$ & 0.40 & 25968.57 & $0.81^{* *}$ & 0.95 & 13286.12 & 0.10 ** \\
\hline $9 \mathrm{~km}$ & 0.30 & 10282.87 & $0.81^{* *}$ & 0.93 & 6399.90 & 0.00 & 0.43 & 11150.27 & 0.80 ** & 0.95 & 6485.29 & $0.04^{* *}$ \\
\hline 12 km & 0.32 & 5596.47 & $0.76^{* *}$ & 0.90 & 3570.68 & 0.01 & 0.46 & 6078.48 & $0.78^{* *}$ & 0.94 & 3720.80 & 0.03 \\
\hline $15 \mathrm{~km}$ & 0.33 & 3496.02 & $0.73^{* *}$ & 0.90 & 2355.67 & 0.01 & 0.48 & 53784.66 & $0.75 * *$ & 0.94 & 2616.84 & 0.02 \\
\hline $18 \mathrm{~km}$ & 0.35 & 2346.47 & $0.69^{* *}$ & 0.89 & 1585.35 & 0.01 & 0.51 & 2544.73 & $0.73^{* *}$ & 0.94 & 1783.82 & 0.00 \\
\hline $21 \mathrm{~km}$ & 0.38 & 1651.19 & $0.65^{* *}$ & 0.87 & 1159.82 & 0.03 & 0.52 & 1818.62 & 0.70 ** & 0.90 & 1231.49 & $0.14^{* *}$ \\
\hline $24 \mathrm{~km}$ & 0.37 & 1241.42 & $0.62^{* *}$ & 0.88 & 895.61 & -0.04 & 0.54 & 1344.45 & $0.68^{* *}$ & 0.92 & 932.27 & -0.03 \\
\hline
\end{tabular}

In contrast, the GWR models seem to be better suited to the investigation of the region thermal environment and the underlying influencing factors (Table 3). For each case, the GWR model exhibited an apparently higher $R^{2}$ value than that of the OLS model. This is further confirmed by the $A I C C$ of each pair of models. If the difference between the $A I C c$ values of the two models is $>3$, then the model with a lower $A I C C$ value can be considered to be the better model. When considering the complexity of the GWR regression algorithm, these results demonstrate that the GWR models function better than the OLS models. Additionally, the GWR models present a more stable performance than the OLS models across different grid sizes and periods. In particular, the significance of these $I$ values for most of the cases $(p>0.05)$ further demonstrated that the prediction results that are produced by GWR models are more applicable to the situation of this study.

\section{Discussion}

\subsection{The Relationships between LST and the Built-Up Density Revealed by the OLS and GWR Models}

This study discussed the potential relationship between LST and underlying physical factors across various spatial scales. The OLS and GWR analyses both confirmed that the underlying physical factors exert a significant impact on the LST variation, as shown in Table 3.

In terms of the spatial-temporal scale, as the most frequently used regression method, the increasing $R^{2}$ of OLS models from 2000 to 2015 indicated that the urban sprawl of the study region further strengthens its influence on the UHI phenomenon. Moreover, notably, various $R^{2}$ values for different spatial analysis units implied that a spatial scale issue does exist in regional UHI studies. Similar findings have been discussed by [17], which recorded a lower strength of linear regressions $\left(R^{2}\right)$ between urban ecological land and LST with an increasing grid size (spatial analysis unit) in the city of Beijing. This gradient effect can be mainly attributed to the changes in sample statistic responses to 
different grain sizes. In other words, most of the studies that focused on the relationship between LST and land surface coverage were inclined to use the average (or other types of statistical indicators) values as the statistical variables that are based on the specific spatial analysis unit $[8,18,36,38]$. The sample size and range (max-min) both narrowed with larger grid sizes, leading to a reduction in the complexity and heterogeneity of the variables for regression analysis, as shown in Figure 5. This generalization with a larger spatial analysis unit is very much in line with the global regression models, i.e., the OLS model [12].
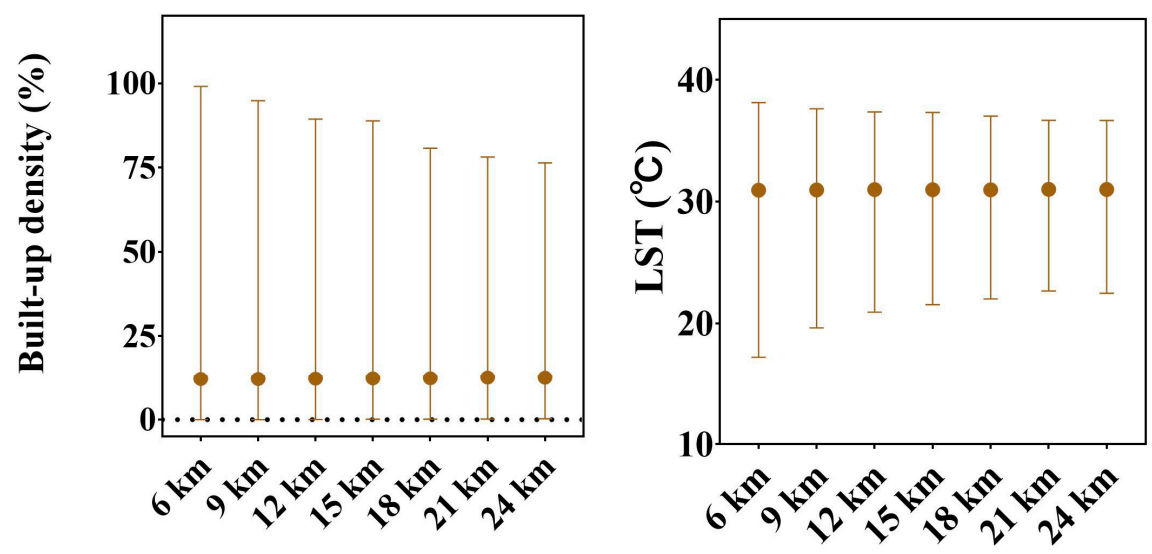

Figure 5. The sample distribution characteristics for the built-up density and LST across different grid size cases in 2015. The dots represent the average value, and the error bars represent the minimum and maximum values.

However, the performance of OLS models was much lower than that of the GWR models. The main reason for this is that, as a classic regression approach, OLS analysis tends to provide an estimate of the general situation for an entire region, regardless of the spatial pattern [47]. In this study, the underlying physical factors and LST in the region of BTH both exhibited significant spatial heterogeneity, as shown in Figures 2 and 3. This will weaken the quantitative expression of the relationship between the two variables in this study, i.e., built-up density and LST, by classic regression methods. Evidence for this can be found in relevant studies. For example, while using global analysis methods, [19,48] found an $R^{2}$ value of $>0.7$ for quantifying the relationship between urban built-up land and LST in a highly developed urban region. In contrast, [13,37] found an $R^{2}$ of nearly 0.5 in order to quantify the OLS regression models for urban built-up land and LST in a region with urban and suburban areas. Subsequently, a further cut in $R^{2}$ was found in this study with a larger region including urban, rural, and natural areas. Moreover, although the OLS regression results are statistically significant $(p<0.01$, Table 3$)$, the $I$ index with the same statistical significance $(p<0.01$, Table 3$)$ further indicates that the OLS model has certain limitations in this study. Because of that, ideal spatial regression prediction results require both the high and low predicted (standard) residuals that are to be randomly distributed [46,49]. Furthermore, the local Moran's I analysis results highlight the obvious spatial clustering characteristics of the standard residual by the OLS models, as shown in Figure 6.

In view of the above, the UHI phenomenon exhibits high spatial heterogeneity for characterizing the thermal content of the underlying surface, which is difficult to characterize with global regression methods. Instead, the GWR model exhibits a better performance than the OSL model for depicting the spatial non-stationarity relationship between LST and underlying variables, with a higher $R^{2}(>0.79)$ and lower AICc (Table 3). Moreover, for most of the cases, the insignificant Moran index $(I)$ indicated that the residuals of the GWR models were randomly distributed, in order to meet the verification of the regression results. Additionally, the local Moran's I analysis showed that the spatial cluster characteristics of the predicting residuals for the GWR model are weaker than those of the OLS model in terms of both breadth and intensity (Figure 6). Specifically, for the OLS model, the cluster areas with high predicted deviation have no obvious spatial regularity, being distributed in all kinds of regions, including urban, rural, and natural regions. On the 
contrary, the cluster regions for the GWR model are mainly distributed in the mountainous areas of the study area. This is understandable, because the global and local regression models have both been argued to provide unexpected results for elevation $[12,29,38]$, and our results also confirmed that the prediction error of the regression model will increase with a higher elevation (Figure 7).

(A)

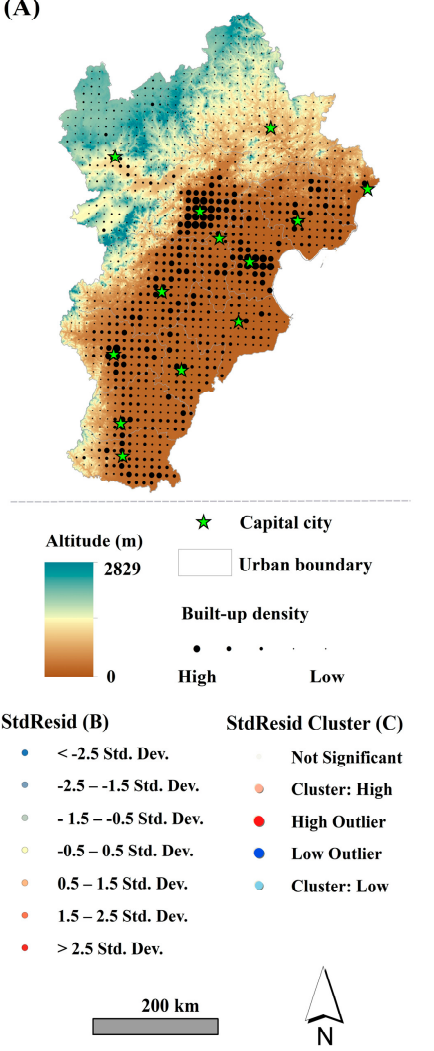

(B)
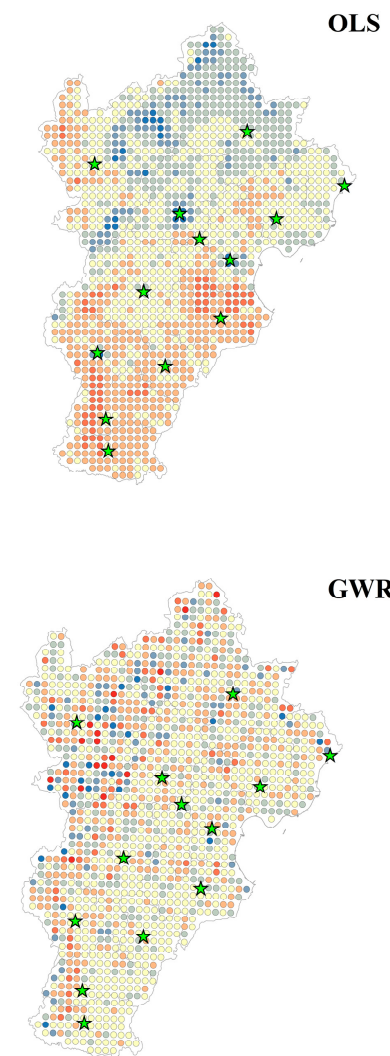

(C)

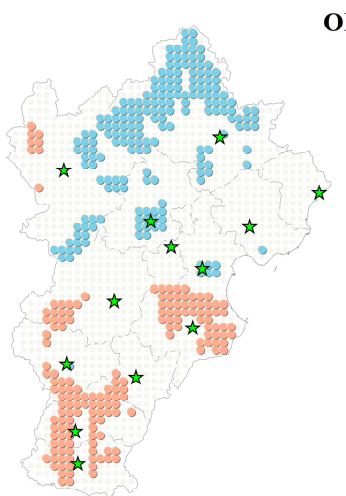

WR

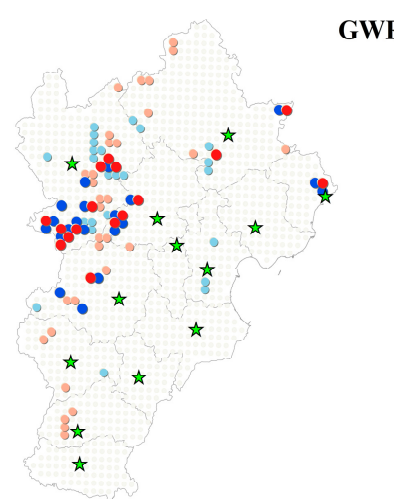

OLS

Figure 6. Spatial statistical plots for the standard residuals (StdResid) of the ordinary least squares (OLS) and geographically weighted regression (GWR) models with the case of $12 \mathrm{~km}$ grid in 2015, (A) Spatial information of the BTH region, (B) Spatial distribution of the StdResid for each grid by the OLS and GWR models, and higher absolute value of StdResid indicate higher deviation of regression prediction, (C) The LISA map (by Anselin local Moran's I analysis) for the StdResid of the OLS and GWR models, of which the red and blue dot clusters represent the spatial cluster of high value and low values of the StdResid respectively.

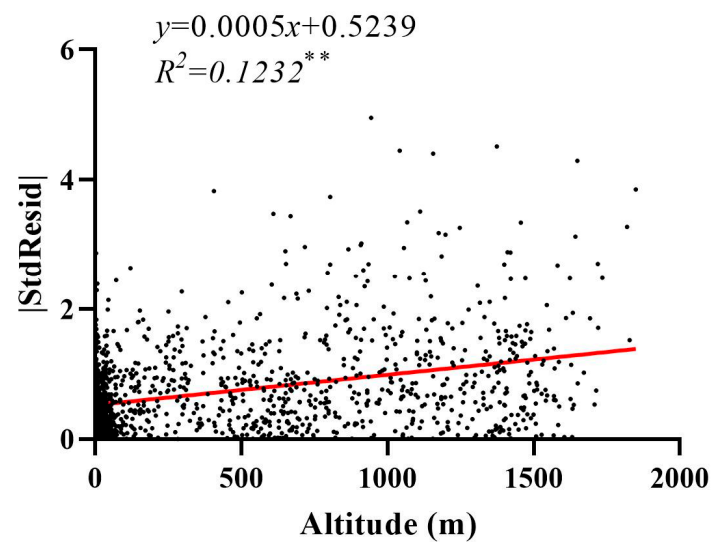

Figure 7. The fitting trend of IStdResid I (the absolute value of standard residuals by the GWR analysis) along with increasing altitude with the case of $12 \mathrm{~km}$ grid in 2015. (** $p<0.01$ level). 


\subsection{Implications and Limitations of this Study}

This study suggests a significant relationship between the LST and built-up density in the BTH region. However, most previous studies have tended to adopt global-based methods to derive the spatial relationship between the spatial variables and UHI phenomenon, as we mentioned above [20]. This may lead relevant studies to overlook the locally detailed differentiation of the underlying mechanisms in large-extent urbanized regions. In addition, the OLS model will further face prediction uncertainties that are caused by various spatial scales, as shown in Table 3. However, for this, there is still no final conclusion on the so-called optimal spatial scale or unit for UHI study, which is still within the limits of the specific case study $[8,18]$. However, what is certain is that the LST and its landscape drivers both present a significant spatial non-stationarity, which indicates that the UHI effect is context-sensitive over space. Therefore, the GWR model seems to outperform an aggregated model in order to depict this non-stationarity with multiscale applicability, by inferring a spatial dynamic approach to parameter estimations. When considering the heterogeneity background that was presented in this study (Figures 2 and 3), to some extent, the GWR analysis can provide more robust information for understanding the interrelation between UHI spatiotemporal variation and landscape dynamics across multiple scales.

However, it is worth noting that this does not mean that the GWR model can be treated as a "perfect" model for subsequent UHI-related studies. Our results also showed that, in the cases with smaller grid sizes, the regression performances of the GWR model are not ideal (i.e., statistically significant $I$ in Table 3). This indicates that GWR also has a certain limitation that is related to the spatial scale, although this limitation is more lenient than that of the OLS method. For studies that focus on a smaller urbanized region, such as an individual city or the core built-up region of a metropolitan area, the heterogeneity and complexity used to describe the land surface thermal environment and landscape characteristics will both be further enhanced, due to the usage of more sophisticated spatial and climate data $[18,50]$. This study adopted seasonal average LST data to avoid the issue of missing data, due to cloudy weather conditions in summer [51,52]. However, this generalization means that our results ignored many research details that are required in studies that are based on air temperature (with a finer temporal resolution) and medium/high resolution remote sensing data (with a finer spatial resolution) [18,53]. In addition, it did not involve the usage of various spatial analysis units, such as a regular grid [47,54], concentric ring [38,55], spatial buffer [13,56], or irregular urban block [37,48], etc. All of these factors will further bring uncertainties for quantifying the relationship between UHI and underlying variables [36]. Beyond that, this study only used the built-up density as the key independent variable for explaining the variation of LST. It has been frequently reported that there are many other types of key factors that have significant impacts on the urban land surface thermal environment, e.g., the landscape pattern index and land surface biophysical parameters [1,6]. Many of these factors have been shown to exhibit various responses to changing spatial analysis scales, which may lead to scaledependent uncertainty in subsequent regression analysis [16]. For addressing these issues, further in-depth spatial-statistical discussions are needed to cover the potential changes in thermal landscape patterns at different grain sizes and in different regional environments, as well as the multi-factor responses, in order to obtain a better understanding of the UHI phenomenon and its associated driving factors across the metropolitan area.

\section{Conclusions}

In this study, we chose a large-extent urban agglomeration-the BTH region in Chinaas the study area. While using multi-temporal land cover and LST data based on remote sensing technology, we examined how the underlying surface characteristics affect the UHI effect in the study area. On this basis, this study further discussed the modeling performance in quantifying the relationship between LST and built-up density across 
various spatial analysis gradients, by comparing the OLS (global) and GWR (local) methods. The main findings can be summarized, as follows.

The OLS and GWR analysis both confirmed that the composition of built-up land contributes as an essential factor that is responsible for the UHI phenomenon in a large urban agglomeration region. The difference is that the OLS model results exhibited a significant (spatial) gradient effect, namely its performance in quantifying the relationship between LST and its driving factors, which changed with different grid sizes (that ranged from 6 to $24 \mathrm{~km}$ ). This also indicated that using a global-based model may generalize and ignore the heterogeneous characteristics of LST and the landscape in a large urbanized region. In contrast, the GWR model revealed considerably stronger relationships in interpreting these driving forces for LST. Moreover, the results showed a robust and lower scale dependence performance for accommodating the spatial non-stationarity in a UHI study than that of the OLS model. In general, our study acts as a supplement to the field that is related to the scale and methodology issues in UHI research. The main findings provide insights into the dynamic causal mechanism between the UHI effect and landscape factors in large extent urban agglomeration areas and, thus, provide useful implications for future UHI studies and site-specific landscape planning.

Author Contributions: Conceptualization, L.Y.; Data curation, J.L. and D.W.; Formal analysis, Y.X.; Funding acquisition, L.Y. and Y.X.; Methodology, N.J.; Resources, J.L. and D.W.; Software, N.J.; Supervision, L.Y.; Validation, Y.X.; Visualization, Y.W. and M.X.; Writing—original draft, L.Y., Y.W. and M.X.; Writing—review \& editing, L.Y. All authors have read and agreed to the published version of the manuscript.

Funding: This study was financed by the National Natural Science Foundation of China (41701206), the Humanities and Social Science project of Ministry of education of China (20YJCZH198), the Natural Science Foundation of Shandong Province (ZR2017BD011) and the China Postdoctoral Science Foundation (2017M622256).

Data Availability Statement: The data presented in this study are available on request from the corresponding author. The data are not publicly available due to the privacy agreement among co-authors.

Acknowledgments: We would sincerely thank the editors and anonymous reviewers, for their valuable advices regarding this manuscript. In particular, the corresponding author would like to extend his personal thank to $\mathrm{Y}$. $\mathrm{Xu}$ and two Y.R. Yao for their extraordinary pleasure and support.

Conflicts of Interest: The authors declare no conflict of interest.

\section{References}

1. $\mathrm{Wu}, \mathrm{Z}$.; Ren, Y. A bibliometric review of past trends and future prospects in urban heat island research from 1990 to 2017. Environ. Rev. 2019, 27, 241-251. [CrossRef]

2. Arnfield, A.J. Two decades of urban climate research: A review of turbulence, exchanges of energy and water, and the urban heat island. Int. J. Clim. 2003, 23, 1-26. [CrossRef]

3. Gago, E.J.; Roldan, J.; Pacheco-Torres, R.; Ordonez, J. The city and urban heat islands: A review of strategies to mitigate adverse effects. Renew. Sustain. Energy Rev. 2013, 25, 749-758. [CrossRef]

4. Manoli, G.; Fatichi, S.; Bou-Zeid, E.; Katul, G.G. Seasonal hysteresis of surface urban heat islands. Proc. Natl. Acad. Sci. USA 2020, 117, 7082-7089. [CrossRef]

5. Nastran, M.; Kobal, M.; Eler, K. Urban heat islands in relation to green land use in European cities. Urban For. Urban Green. 2019, 37, 33-41. [CrossRef]

6. Deilami, K.; Kamruzzaman, M.; Liu, Y. Urban heat island effect: A systematic review of spatio-temporal factors, data, methods, and mitigation measures. Int. J. Appl. Earth Obs. Geoinf. 2018, 67, 30-42. [CrossRef]

7. Chen, A.; Sun, R.; Chen, L. Studies on urban heat island from a landscape pattern view: A review. Acta Ecol. Sin. 2012, 32, 4553-4565. [CrossRef]

8. Chen, A.; Yao, L.; Sun, R.; Li, J. How many metrics are required to identify the effects of the landscape pattern on land surface temperature? Ecol. Indic. 2014, 45, 424-433. [CrossRef]

9. Kaufmann, R.K.; Seto, K.C.; Schneider, A.; Liu, Z.; Zhou, L.; Wang, W. Climate Response to Rapid Urban Growth: Evidence of a Human-Induced Precipitation Deficit. J. Clim. 2007, 20, 2299-2306. [CrossRef]

10. Amanollahi, J.; Tzanis, C.G.; Ramli, M.; Abdullah, A.M. Urban heat evolution in a tropical area utilizing Landsat imagery. Atmos. Res. 2016, 167, 175-182. [CrossRef] 
11. Forman, R.; Godron, M. Landscape Ecology; John Wiley and Sons: New York, NY, USA, 1986.

12. Zhao, C.; Jensen, J.L.R.; Weng, Q.; Weaver, R. A Geographically Weighted Regression Analysis of the Underlying Factors Related to the Surface Urban Heat Island Phenomenon. Remote Sens. 2018, 10, 1428. [CrossRef]

13. Li, X.; Zhou, W. Spatial patterns and driving factors of surface urban heat island intensity: A comparative study for two agriculture-dominated regions in China and the USA. Sustain. Cities Soc. 2019, 48, 48. [CrossRef]

14. Liang, Z.; Wu, S.; Wang, Y.; Wei, F.; Huang, J.; Shen, J.; Li, S. The relationship between urban form and heat island intensity along the urban development gradients. Sci. Total Environ. 2020, 708, 135011. [CrossRef] [PubMed]

15. Grimm, N.B.; Foster, D.; Groffman, P.; Grove, J.M.; Hopkinson, C.S.; Nadelhoffer, K.J.; Pataki, D.E.; Peters, D.P. The changing landscape: Ecosystem responses to urbanization and pollution across climatic and societal gradients. Front. Ecol. Environ. 2008, 6, 264-272. [CrossRef]

16. Yuan, S.; Xia, H.; Yang, L. How changing grain size affects the land surface temperature pattern in rapidly urbanizing area: A case study of the central urban districts of Hangzhou City, China. Environ. Sci. Pollut. Res. 2020, 1-15. [CrossRef] [PubMed]

17. Peng, J.; Xie, P.; Liu, Y.; Ma, J. Urban thermal environment dynamics and associated landscape pattern factors: A case study in the Beijing metropolitan region. Remote Sens. Environ. 2016, 173, 145-155. [CrossRef]

18. Zhou, W.; Qian, Y.; Li, X.; Li, W.; Han, L. Relationships between land cover and the surface urban heat island: Seasonal variability and effects of spatial and thematic resolution of land cover data on predicting land surface temperatures. Landsc. Ecol. 2014, 29, 153-167. [CrossRef]

19. Yao, L.; Xu, Y.; Zhang, B. Effect of urban function and landscape structure on the urban heat island phenomenon in Beijing, China. Landsc. Ecol. Eng. 2019, 15, 379-390. [CrossRef]

20. Deilami, K.; Kamruzzaman, M.; Hayes, J.F. Correlation or Causality between Land Cover Patterns and the Urban Heat Island Effect? Evidence from Brisbane, Australia. Remote Sens. 2016, 8, 716. [CrossRef]

21. National Bureau of Statistics. China City Statistical Yearbook; China Statistical Press: Beijing, China, 2015.

22. Li, X.; Kuang, W. Spatio-Temporal Trajectories of Urban Land Use Change during 1980-2015 and Future Scenario Simulation in Beijing-Tianjin-Hebei Urban Agglomeration. Econ. Geogr. 2019, 39, 187-194, 200. [CrossRef]

23. Zhao, N.; Jiao, Y.; Ma, T.; Zhao, M.; Fan, Z.; Yin, X.; Liu, Y.; Yue, T. Estimating the effect of urbanization on extreme climate events in the Beijing-Tianjin-Hebei region, China. Sci. Total Environ. 2019, 688, 1005-1015. [CrossRef] [PubMed]

24. Kang, S.; Eltahir, E.A.B. North China Plain threatened by deadly heatwaves due to climate change and irrigation. Nat. Commun. 2018, 9, 1-9. [CrossRef]

25. Wang, D.; Sang, M.; Huang, Y.; Chen, L.; Wei, X.; Chen, W.; Wang, F.; Liu, J.; Hu, B. Trajectory analysis of agricultural lands occupation and its decoupling relationships with the growth rate of non-agricultural GDP in the Jing-Jin-Tang region, China. Environ. Dev. Sustain. 2018, 21, 799-815. [CrossRef]

26. Yu, W.; Zhou, W.; Qian, Y.; Yan, J. A new approach for land cover classification and change analysis: Integrating backdating and an object-based method. Remote Sens. Environ. 2016, 177, 37-47. [CrossRef]

27. Wan, Z.; Zhang, Y.; Zhang, Q.; Li, Z.-L. Validation of the land-surface temperature products retrieved from Terra Moderate Resolution Imaging Spectroradiometer data. Remote Sens. Environ. 2002, 83, 163-180. [CrossRef]

28. Rigo, G.; Parlow, E.; Oesch, D. Validation of satellite observed thermal emission with in-situ measurements over an urban surface. Remote Sens. Environ. 2006, 104, 201-210. [CrossRef]

29. Zhou, D.; Zhao, S.; Zhang, L.; Sun, G.; Liu, Y. The footprint of urban heat island effect in China. Sci. Rep. 2015, 5, 11160. [CrossRef]

30. Liu, F.; Zhang, X.; Murayama, Y.; Morimoto, T. Impacts of Land Cover/Use on the Urban Thermal Environment: A Comparative Study of 10 Megacities in China. Remote Sens. 2020, 12, 307. [CrossRef]

31. Zhou, D.; Zhang, L.; Li, D.; Huang, D.; Zhu, C. Climate-vegetation control on the diurnal and seasonal variations of surface urban heat islands in China. Environ. Res. Lett. 2016, 11, 074009. [CrossRef]

32. $\mathrm{Wu}, \mathrm{J}$. Effects of changing scale on landscape pattern analysis: Scaling relations. Landsc. Ecol. 2004, 19, 125-138. [CrossRef]

33. Zhang, Q.; Wu, Z.; Zhang, H.; Fontana, G.D.; Tarolli, P. Identifying dominant factors of waterlogging events in metropolitan coastal cities: The case study of Guangzhou, China. J. Environ. Manag. 2020, 271, 110951. [CrossRef]

34. Cadenasso, M.L.; Pickett, S.T.A.; Schwarz, K. Spatial heterogeneity in urban ecosystems: Reconceptualizing land cover and a framework for classification. Front. Ecol. Environ. 2007, 5, 80-88. [CrossRef]

35. Li, X.; Zhou, W. Optimizing urban greenspace spatial pattern to mitigate urban heat island effects: Extending understanding from local to the city scale. Urban For. Urban Green. 2019, 41, 255-263. [CrossRef]

36. Yao, L.; Li, T.; Xu, M.; Xu, Y. How the landscape features of urban green space impact seasonal land surface temperatures at a city-block-scale: An urban heat island study in Beijing, China. Urban For. Urban Green. 2020, 52, 126704. [CrossRef]

37. Zhou, W.; Huang, G.; Cadenasso, M.L. Does spatial configuration matter? Understanding the effects of land cover pattern on land surface temperature in urban landscapes. Landsc. Urban Plan. 2011, 102, 54-63. [CrossRef]

38. Hou, H.; Estoque, R.C. Detecting Cooling Effect of Landscape from Composition and Configuration: An Urban Heat Island Study on Hangzhou. Urban For. Urban Green. 2020, 53, 126719. [CrossRef]

39. Imhoff, M.L.; Zhang, P.; Wolfe, R.E.; Bounoua, L. Remote sensing of the urban heat island effect across biomes in the continental USA. Remote Sens. Environ. 2010, 114, 504-513. [CrossRef]

40. Meng, Q.; Zhang, L.; Sun, Z.; Meng, F.; Wang, L.; Sun, Y. Characterizing spatial and temporal trends of surface urban heat island effect in an urban main built-up area: A 12-year case study in Beijing, China. Remote Sens. Environ. 2018, 204, 826-837. [CrossRef] 
41. Peng, J.; Jiansheng, W.; Liu, Y.; Li, H.; Wu, J. Seasonal contrast of the dominant factors for spatial distribution of land surface temperature in urban areas. Remote Sens. Environ. 2018, 215, 255-267. [CrossRef]

42. Sun, R.; Lü, Y.; Li, J.; Yang, L.; Chen, A. Assessing the stability of annual temperatures for different urban functional zones. Build. Environ. 2013, 65, 90-98. [CrossRef]

43. Buyantuyev, A.; Wu, J. Urban heat islands and landscape heterogeneity: Linking spatiotemporal variations in surface temperatures to land-cover and socioeconomic patterns. Landsc. Ecol. 2010, 25, 17-33. [CrossRef]

44. Zhang, L.; Gove, J.H.; Heath, L.S. Spatial residual analysis of six modeling techniques. Ecol. Model. 2005, 186, 154-177. [CrossRef]

45. Wang, X.; Zhou, T.; Tao, F.; Zang, F. Correlation Analysis between UBD and LST in Hefei, China, Using Luojia1-01 Night-Time Light Imagery. Appl. Sci. 2019, 9, 5224. [CrossRef]

46. Mitchel, A. The ESRI Guide to GIS Analysis, Volume 2: Spatial Measurements and Statistics; Esri Press: Redlands, CA, USA, 2005.

47. Sun, R.; Xie, W.; Li, J. A landscape connectivity model to quantify contributions of heat sources and sinks in urban regions. Landsc. Urban Plan. 2018, 178, 43-50. [CrossRef]

48. $\mathrm{Wu}, \mathrm{Z} . ;$ Yao, L.; Ren, Y. Characterizing the spatial heterogeneity and controlling factors of land surface temperature clusters: A case study in Beijing. Build. Environ. 2020,169, 106598. [CrossRef]

49. Stewart Fotheringham, A.; Charlton, M.; Brunsdon, C. The geography of parameter space: An investigation of spatial nonstationarity. Int. J. Geogr. Inf. Syst. 1996, 10, 605-627. [CrossRef]

50. Weng, Q.; Lu, D.; Schubring, J. Estimation of land surface temperature-vegetation abundance relationship for urban heat island studies. Remote Sens. Environ. 2004, 89, 467-483. [CrossRef]

51. Zhang, X.; Zhou, J.; Liang, S.; Chai, L.; Wang, D.; Liu, J. Estimation of 1-km all-weather remotely sensed land surface temperature based on reconstructed spatial-seamless satellite passive microwave brightness temperature and thermal infrared data. ISPRS J. Photogramm. Remote Sens. 2020, 167, 321-344. [CrossRef]

52. Yoo, C.; Im, J.; Cho, D.; Yokoya, N.; Xia, J.; Bechtel, B. Estimation of All-Weather 1 km MODIS Land Surface Temperature for Humid Summer Days. Remote Sens. 2020, 12, 1398. [CrossRef]

53. Venter, Z.S.; Brousse, O.; Esau, I.; Meier, F. Hyperlocal mapping of urban air temperature using remote sensing and crowdsourced weather data. Remote Sens. Environ. 2020, 242, 111791. [CrossRef]

54. Liu, Y.; Peng, J.; Wang, Y. Efficiency of landscape metrics characterizing urban land surface temperature. Landsc. Urban Plan. 2018, 180, 36-53. [CrossRef]

55. Qiao, Z.; Wu, C.; Zhao, D.; Xu, X.; Yang, J.; Li, F.; Sun, Z.; Liu, L. Determining the Boundary and Probability of Surface Urban Heat Island Footprint Based on a Logistic Model. Remote Sens. 2019, 11, 1368. [CrossRef]

56. Chen, A.; Yao, X.A.; Sun, R.; Chen, L. Effect of urban green patterns on surface urban cool islands and its seasonal variations. Urban For. Urban Green. 2014, 13, 646-654. [CrossRef] 